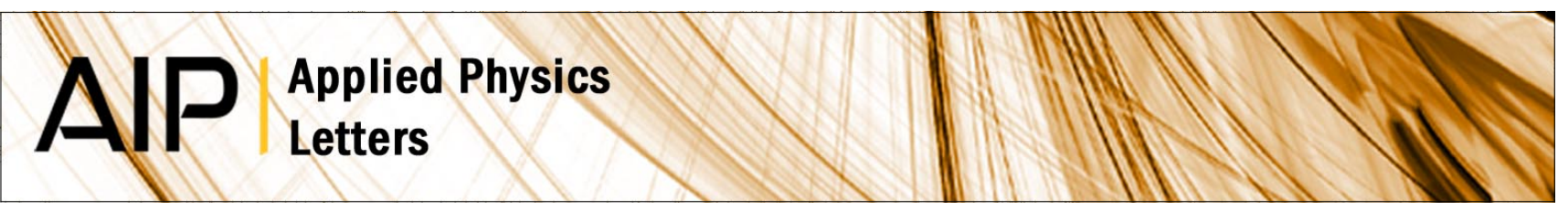

\title{
P-type semiconducting gas sensing behavior of nanoporous rf sputtered CaCu3Ti4012 thin films
}

E. Joanni, R. Savu, P. R. Bueno, E. Longo, and J. A. Varela

Citation: Appl. Phys. Lett. 92, 132110 (2008); doi: 10.1063/1.2905810

View online: http://dx.doi.org/10.1063/1.2905810

View Table of Contents: http://apl.aip.org/resource/1/APPLAB/v92/i13

Published by the AIP Publishing LLC.

Additional information on Appl. Phys. Lett.

Journal Homepage: http://apl.aip.org/

Journal Information: http://apl.aip.org/about/about_the_journal

Top downloads: http://apl.aip.org/features/most_downloaded

Information for Authors: http://apl.aip.org/authors

\section{ADVERTISEMENT}
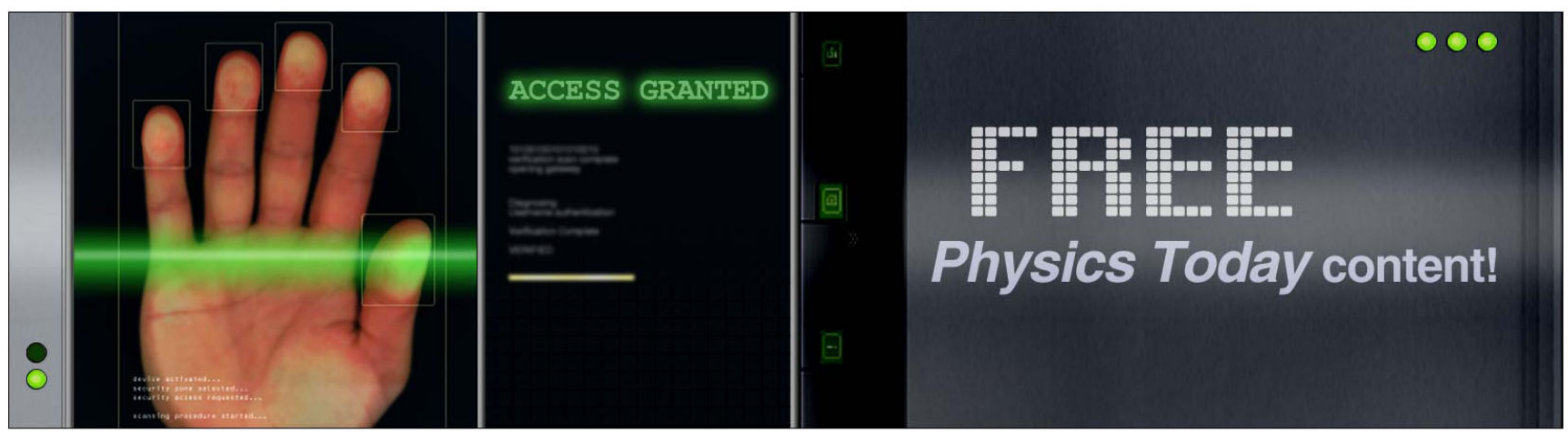


\title{
$P$-type semiconducting gas sensing behavior of nanoporous rf sputtered $\mathrm{CaCu}_{3} \mathrm{Ti}_{4} \mathrm{O}_{12}$ thin films
}

\author{
E. Joanni, ${ }^{a)}$ R. Savu, P. R. Bueno, ${ }^{a)}$ E. Longo, and J. A. Varela \\ LIEC-Laboratório Interdisciplinar de Eletroquímica e Cerâmica, Departamento de Físico-Química, \\ UNESP_Universidade Estadual Paulista, Araraquara, São Paolo 14800-900, Brazil
}

(Received 4 January 2008; accepted 10 March 2008; published online 4 April 2008)

The fabrication of nanoporous sputtered $\mathrm{CaCu}_{3} \mathrm{Ti}_{4} \mathrm{O}_{12}$ thin films with high gas sensitivity is reported
in this work. The porous microstructure and the nanocrystalline nature of the material promoted the
diffusion of the atmosphere into the film, shortening the response time of the samples. Behaving as
-type semiconductor, the material presents enhanced sensitivity even at low working temperatures.
Impedance spectroscopy measurements were performed in order to investigate the mechanisms
responsible for the performance of the devices. (C) 2008 American Institute of Physics. [DOI: $10.1063 / 1.2905810]$

Since the first reports by Subramanian et al. ${ }^{1}$ and Sinclair et al., ${ }^{2}$ the high values of dielectric constant and nonOhmic behavior in $\mathrm{CaCu}_{3} \mathrm{Ti}_{4} \mathrm{O}_{12}$ (CCTO) ceramics have attracted a great deal of attention for applications in capacitors, varistors, and other electronic devices. ${ }^{1-14}$ Although the internal barrier layer capacitance model has gradually been accepted as the most plausible mechanism for explaining the dielectric behavior of $\mathrm{CCTO},{ }^{2,6,10,13,14}$ the origin of its properties is still the subject of some controversy. ${ }^{1-11}$ For polycrystalline devices, grain boundaries, twin boundaries or dislocation networks, ${ }^{2,3,5-7}$ all of them possessing space charge nature, appear to be the major elements contributing to the total dielectric response. ${ }^{3}$ Chung et al. $^{4}$ observed a Schottkytype potential barrier in the grain boundary regions, supported by evidence from other works. $3,9,15$

CCTO thin films obtained by metal-organic chemicalvapor deposition and chemical solution deposition presented irregular grain sizes and rough surfaces with no measurements reported. ${ }^{16,17}$ Sol-gel films deposited over $\mathrm{Si} / \mathrm{SiO}_{2} / \mathrm{Ti} / \mathrm{Pt}$ substrates and heat treated at $650{ }^{\circ} \mathrm{C}$ presented low dielectric constant values due to the small differences in conductivity between grains and grain boundaries when compared to bulk samples. ${ }^{18}$ Pulsed laser deposition (PLD) on single crystalline substrates promoted epitaxial growth in the $\langle 001\rangle$ direction, with dielectric constants only one order of magnitude smaller than the ones for bulk samples. ${ }^{19}$ Polycrystalline films made by the same method over $\mathrm{Si} / \mathrm{SiO}_{2} / \mathrm{Ti} / \mathrm{Pt}$ substrates presented $k$ in the range of 1000-2500, even with a $\mathrm{LaNiO}_{3}$ buffer layer between the CCTO and the electrodes. ${ }^{20-22}$

The mechanisms responsible for the remarkable dielectric properties of CCTO can be exploited in gas-sensing applications since the interactions between the material and the surrounding atmosphere are bound to induce variations in the grain boundary barrier height, thus promoting gas sensitivity. Until now, Kim et al. were the only researchers to report the performance of CCTO as a gas sensor. The authors used microsphere templating in order to increase the exposed surface area of films made by PLD. ${ }^{23}$

\footnotetext{
${ }^{\text {a) }}$ Authors to whom correspondence should be addressed. Electronic addresses: ednan_joanni@yahoo.com and prbueno@iq.unesp.br.
}

In this work, we present results for nanoporous sputtered CCTO thin film gas sensors with enhanced sensitivity and response times, even at low working temperatures. Impedance spectroscopy measurements were performed in order to investigate the mechanisms responsible for the performance of the devices.

The 2 in. diameter CCTO sputtering target was prepared through the mixed oxide route and the substrates used in the process were $\mathrm{Si} / \mathrm{SiO}_{2} / \mathrm{Ti} / \mathrm{Pt}$. The metallic films were deposited in a planar configuration achieved with a shadow mask, giving rise to a $2 \mathrm{~mm}$ gap between the electrodes. CCTO nanocrystalline thin films (approximately $200 \mathrm{~nm}$ thick) were deposited at room temperature in $4 \times 10^{-2}$ Torr argon pressure and $150 \mathrm{~W}$ rf power. After the deposition, the films were heat treated at $700{ }^{\circ} \mathrm{C}$ in pure oxygen for $30 \mathrm{~min}$ with heating and cooling rates of $15^{\circ} \mathrm{C} / \mathrm{min}$.

The degree of crystallinity and the phases present in the films were assessed by x-ray diffraction (XRD) (Rigaku Rint 2000). For observing the size and shape of the grains as well as the porosity of the films, atomic force microscopy (AFM) (Digital Instruments NanoScope IIIa) measurements were carried out. The impedance and electrical resistance measurements were carried out at temperatures in the range from

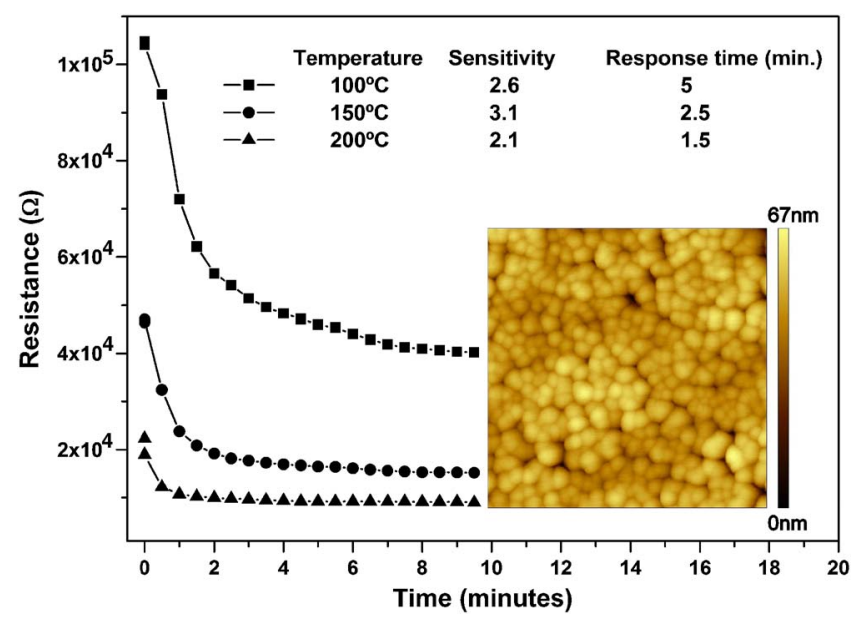

FIG. 1. (Color online) Gas sensing behavior at different temperatures upon introduction of $\mathrm{O}_{2}$ in the test chamber. The inset shows an AFM image of a CCTO film. Image dimensions are $1 \times 1 \mu \mathrm{m}$. 

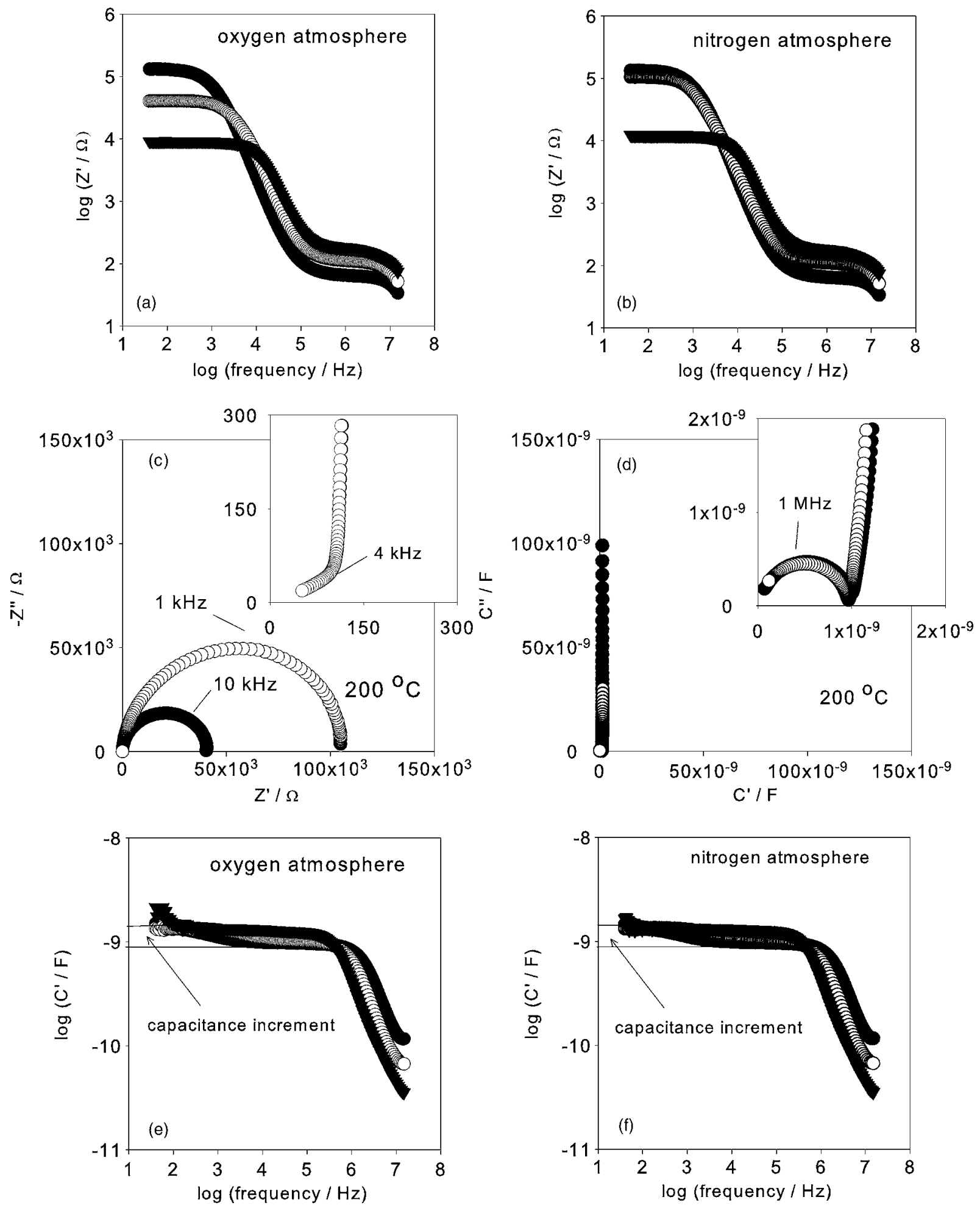

FIG. 2. Bode impedance diagrams in oxygen (a) and nitrogen (b) atmospheres at three different temperatures, i.e., $(\bullet) 25^{\circ} \mathrm{C}$, $(\bigcirc) 100{ }^{\circ} \mathrm{C}$, and $(\boldsymbol{\nabla}) 200{ }^{\circ} \mathrm{C}$. (c) and (d) are the complex impedance and capacitance diagrams at $200{ }^{\circ} \mathrm{C}$ for $(-)$ oxygen and $(\bigcirc)$ nitrogen atmospheres, respectively. The inset figures account for the high-frequency region. (e) and (f) are the Bode capacitive diagrams at the same temperatures and atmospheres of (a) and (b) respectively.

100 to $200{ }^{\circ} \mathrm{C}$, at atmospheric pressure, in $\mathrm{O}_{2}$ and $\mathrm{N}_{2}$, using an impedance analyzer (Agilent 4294A) in the frequency range from $40 \mathrm{~Hz}$ to $110 \mathrm{MHz}$ with an amplitude of $100 \mathrm{mV}$. The samples were kept in 100 SCCM (SCCM denotes cubic centimeter per minute at STP) $\mathrm{N}_{2}$ until the temperature was stabilized; at this point, the nitrogen flow was stopped, $100 \mathrm{SCCM} \mathrm{O}_{2}$ was injected in the chamber and the measurements were started.

$\mathrm{x}$-ray diffraction results (graphs not shown here) reveal that the films deposited at room temperature are amorphous, as expected. After the heat treatment, the main peaks in the diffractogram can be assigned to CCTO, with residual peaks from titanium and copper oxides.

The grains, as observed by AFM (inset of Fig. 1), are equiaxial, exhibiting uniform sizes (approximately $50 \mathrm{~nm}$ ). The microstructure reveals a good degree of porosity which promoted the diffusion of the atmosphere into the film, enhancing the gas sensing properties of the samples, as discussed below. 
Figure 1 shows the change in the electrical resistance at different temperatures upon introduction of oxygen in the test chamber. The observed decrease in resistivity is a clear indication of $p$-type conductivity. Kim et al. reported an opposite response for their films, ${ }^{23}$ in agreement with most results in the literature for CCTO ceramics. However, recently Deng et al. performed Hall effect measurements on CCTO ceramics and PLD thin films with $p$-type conductivity being observed for all samples. ${ }^{24}$ The authors state that such $p$-type conductivity could be introduced by point defects such as copper deficiencies or valence changes of copper and/or titanium ions in the CCTO lattice, ${ }^{24}$ as supported by evidence reported in other works. ${ }^{25,26}$

Important gas sensing characteristics, shown in the table in Fig. 1, are the sensitivity and response time of our devices. The sensitivity, defined as the ratio between the resistance in nitrogen and in oxygen, proved to be high when compared with the values obtained by Kim et $a l^{23}$ The response time of the samples, calculated as the time necessary to reach $90 \%$ of the final value, was 5, 2.5, and $1.5 \mathrm{~min}$ for 100,150 , and $200{ }^{\circ} \mathrm{C}$, respectively. Although the measurements cannot be directly compared due to differences in device configuration and testing atmosphere, our results compare favorably with the ones obtained by Kim et al. ${ }^{23}$ Their lower sensitivity (approximately 1.2) and long response time (more than $1 \mathrm{~h}$ ) were measured at the relatively high temperature of $300{ }^{\circ} \mathrm{C}$. The sensitivity of the porous sputtered films is comparatively very high, but our most striking result is the fast response times, even with the films being deposited directly on the substrate. This performance is due to the enhanced porosity that leads to an open structure, with the grain boundaries more exposed to the surrounding atmosphere. For those reasons, the response of our devices, even at the low working temperature of $100{ }^{\circ} \mathrm{C}$, was superior in terms of surface activity and gas sensitivity without the need for microsphere templating.

Figures 2(a) and 2(b) show the Bode complex impedance diagrams at different temperatures for oxygen and nitrogen atmospheres, respectively. The high-frequency region accounts for the CCTO/electrode junction, which increases its resistance as a function of temperature, as expected. On the other hand, the region of lower frequencies (lower than $10^{4} \mathrm{~Hz}$ ) shows an inverse behavior. This range accounts for grain-grain junctions and controls the global conductivity response, being strongly related to the gas sensing mechanism. By comparing Figs. 2(a) and 2(b) for all temperatures, the effect of $\mathrm{N}_{2}$ is always to cause a decrease in the low frequency de conductivity of the CCTO films. Figure 2(c) shows the complex impedance diagrams at $200{ }^{\circ} \mathrm{C}$ for oxygen and nitrogen atmospheres. As expected, the $\mathrm{N}_{2}$ atmosphere causes a decrease in the dc conductivity, confirming the $p$-type behavior. As can be seen in the inset of Fig. 2(c) and confirmed by the comparison of Figs. 2(a) and 2(b), the high-frequency region, accounting for the electrode effect, is not affected by the type of gas for all working temperatures used. Moreover, the complex capacitive diagram [Fig. 2(a)] indicates once again that the capacitance of the electrodes is hardly affected by the atmosphere.

Figures 2(e) and 2(f) show the Bode capacitive diagrams, confirming the effects of temperature and atmosphere, but there is also an additional effect on the capaci- tance from intermediate to low frequencies. Such a relaxation pattern can be described by an equivalent circuit consistent with three parallel contributions: the "highfrequency" limit related to grain boundary capacitances, the complex incremental capacitance at intermediate frequencies related to the relaxation of the particular structure found in the space charge region, and finally, in the low frequency region, the term representing the dc conductance of the multijunction device.

In summary, we reported the fabrication of sputtered CCTO thin film exhibiting $p$-type semiconductive behavior. The nanocrystalline porous microstructure favors the access of the atmosphere to the grain junctions leading to enhanced sensitivities and response times, even at low working temperatures. Impedance spectroscopy analysis reveals a complex pattern with at least two relaxation processes related to the gas sensing mechanism in addition to the one for the CCTO/electrode junction, which is not affected by the gas atmosphere.

Support from the Brazilian research funding agencies FAPESP and CNPq is gratefully acknowledged.

${ }^{1}$ M. A. Subramanian, D. Li, N. Duan, B. A. Reisner, and A. W. Sleight, J. Solid State Chem. 151, 323 (2000).

${ }^{2}$ D. C. Sinclair, T. B. Adams, F. D. Morrison, and A. R. West, Appl. Phys. Lett. 80, 2153 (2002).

${ }^{3}$ P. R. Bueno, M. A. Ramírez, J. A. Varela, and E. Longo, Appl. Phys. Lett. 89, 191117 (2006).

${ }^{4}$ S.-Y. Chung, I.-D. Kim, and S.-J. L. Kang, Nat. Mater. 3, 774 (2004).

${ }^{5}$ L. Fang, M. R. Shen, and W. W. Cao, J. Appl. Phys. 95, 6483 (2004).

${ }^{6}$ T. T. Fang and C. P. Liu, Chem. Mater. 17, 5167 (2005).

${ }^{7}$ T. T. Fang and H. K. Shiau, J. Am. Ceram. Soc. 87, 2072 (2004).

${ }^{8}$ A. P. Ramirez, M. A. Subramanian, M. Gardel, G. Blumberg, D. Li, T. Vogt, and S. M. Shapiro, Solid State Commun. 115, 217 (2000).

${ }^{9}$ M. A. Ramírez, P. R. Bueno, J. A. Varela, and E. Longo, Appl. Phys. Lett. 89, 212102 (2006).

${ }^{10}$ J. L. Zhang, P. Zheng, C. L. Wang, M. L. Zhao, J. C. Li, and J. F. Wang, Appl. Phys. Lett. 87, 142901 (2005).

${ }^{11}$ L. Zhang, Appl. Phys. Lett. 87, 022907 (2005).

${ }^{12}$ A. R. West, T. B. Adams, F. D. Morrison, and D. C. Sinclair, J. Eur. Ceram. Soc. 24, 1439 (2004).

${ }^{13}$ D. Capsoni, M. Bini, V. Massarotti, G. Chiodelli, M. C. Mozzatic, and C. B. Azzoni, J. Solid State Chem. 177, 4494 (2004).

${ }^{14}$ G. Chiodelli, V. Massarotti, D. Capsoni, M. Bini, C. B. Azzoni, M. C. Mozzati, and P. Lupotto, Solid State Commun. 132, 241 (2004).

${ }^{15}$ V. P. B. Marques, P. R. Bueno, A. Z. Simoes, M. Cilense, J. A. Varela, E. Longo, and E. R. Leite, Solid State Commun. 138, 1 (2006).

${ }^{16}$ R. L. Nigro, R. G. Toro, G. Malandrino, I. L. Fragalà, P. Fiorenza, and V. Raineri, Thin Solid Films 515, 6470 (2007).

${ }^{17}$ L. Feng, Y. Wang, Y. Yan, G. Cao, and Z. Jiao, Appl. Surf. Sci. 253, 2268 (2006).

${ }^{18}$ R. Jimenez, M. L. Calzada, I. Bretos, J. C. Goes, and A. S. B. Sombra, J. Eur. Ceram. Soc. 27, 3829 (2007).

${ }^{19}$ Y. Lin, Y. B. Chen, T. Garret, S. W. Liu, C. L. Chen, L. Chen, R. P. Bontchev, A. Jacobson, J. C. Jiang, E. I. Meletis, J. Horwitz, and H.-D. Wu, Appl. Phys. Lett. 81, 631 (2002).

${ }^{20}$ L. Fang and M. Shen, Thin Solid Films 440, 60 (2003).

${ }^{21}$ L. Fang, M. Shen, and W. Cao, J. Appl. Phys. 95, 6483 (2004).

${ }^{22}$ L. Fang, M. Shen, and D. Yao, Appl. Phys. A: Mater. Sci. Process. 80, 1763 (2005)

${ }^{23}$ I.-D. Kim, A. Rothschild, T. Hyodo, and H. L. Tuller, Nano Lett. 6, 193 (2006).

${ }^{24}$ G. Deng, T. Yamada, and P. Muralt, Appl. Phys. Lett. 91, 202903 (2007).

${ }^{25}$ S. Sarkar, P. K. Jana, and B. K. Chaudhuri, Appl. Phys. Lett. 89, 212905 (2006).

${ }^{26}$ T. B. Adams, D. C. Sinclair, and A. R. West, J. Am. Ceram. Soc. 89, 2833 (2006). 